\title{
Technology-enhanced Feedback Profiles and their Associations with Learning and Academic Well-being Indicators in Basic Education
}

\author{
Sanna Elina Oinas \\ Centre for Educational Assessment, Faculty of Educational Sciences, University of Helsinki, Finland \\ ORCID: 0000-0003-4565-4318 \\ Helena Thuneberg \\ Centre for Educational Assessment, Faculty of Educational Sciences, University of Helsinki, Finland \\ ORCID: 0000-0002-6213-3509 \\ Mari-Pauliina Vainikainen \\ Faculty of Education and Culture, University of Tampere, Finland \\ University of Tampere, Finland \\ ORCID: 0000-0003-4186-692X \\ Risto Hotulainen \\ Centre for Educational Assessment, Faculty of Educational Sciences, University of Helsinki, Finland \\ ORCID: 0000-0002-2198-4040
}

Received: 26 Jan 2020

Accepted: 12 Apr 2020

\begin{abstract}
As a variety of commercial educational applications are currently being taken into daily use to provide technology-enhanced feedback, research is needed to observe whether pedagogical evidence of the impact of feedback on learning and well-being is being utilized. To this end, this study explores the connections between technology-enhanced feedback, motivation, competence and the relationship with teachers. A nationally representative sample of pupils undertaking Finnish basic education $(N=2031)$ was analyzed using latent profile analysis. Seven patterns for receiving technology-enhanced feedback were identified. Most girls ( $80 \%$ ) and boys $(55 \%)$ belonged to groups receiving mainly positive feedback in the form of teacher praise, which was connected to the highest scores in all measured indicators. Although the results indicate teachers' efforts to encourage pupils through technology-enhanced feedback, we also identified profiles in which pupils (up to $30 \%$ ) repeatedly received negative feedback related to behavior problems or forgotten matters, as well as profiles in which pupils (5\%) reported that they never received any technology-enhanced feedback at all. Pupils who did not receive any feedback reported the lowest values in all scales. The relationship with teachers was particularly weak for pupils receiving negative feedback or no feedback. The results indicate that current technology-enhanced feedback practices do not fully meet pedagogical knowledge concerning efficient feedback.
\end{abstract}

Keywords: technology-enhanced feedback, motivation, competence, academic well-being

\section{INTRODUCTION}

Technology allows teachers to deliver feedback to pupils with ease via computers and smartphones, as there are several online applications available for feedback purposes (Cutumisu, Chin, \& Schwartz, 2019; ElShaer, Casanova, Freestone, \& Calabrese, 2019; Jeno, Grytnes, \& Vandvik, 2017; McKenna, Pouska, Moraes, \& 
Folkestad, 2019). According to Reeve, Ryan, Deci, and Jang (2009), teachers can support pupils' learning and well-being by providing informative and encouraging feedback instead of using controlling and pressuring language. At school, teachers' feedback practices influence pupils' motivation (Ryan \& Deci, 2000a), ability beliefs (Harter, 2012) and their relationship with teachers (Corno, 2009; Griffin, 2018; Schenke, Ruzek, Lam, Karabenick, \& Eccles, 2018). As recent findings show that pupils are encouraged differently by technologyenhanced feedback delivered online (Oinas, Vainikainen, \& Hotulainen, 2017, 2018), this study evaluates whether different patterns of receiving technology-enhanced feedback are connected to the learning and academic well-being of pupils. In the present study, pupils' school achievement and perceived motivation as indicators of learning, and their relationship with teachers and competence as an indicator of academic wellbeing are evaluated in accordance with technology-enhanced feedback received from the teacher, since feedback is shown to mediate cognitive and affective factors simultaneously (Pekrun, Cusack, Murayma, Elliot, \&Thomas, 2014).

The impact of feedback on learning cannot be regarded as a simple, straightforward phenomenon as, for example, individual differences (Kluger \& DeNisi, 1996; Wiliam, 2011), previous learning experiences (Hughes, 2010), and the teacher-pupil relationship (Cochran, Reinsvold, \& Hess, 2017) influence how the given feedback is interpreted. Feedback provided by teachers has a connection to adopted learning goals and self-concept (Ryan \& Deci, 2000a), when a pupil regards school and teachers as significant (Harter, 2012). As the feedback application is located alongside other applications in a young person's smartphone, it may be that feedback is perceived as representing social acceptance from the teacher (Heimo, Rantanen \& Kimppa, 2015), even comparable with "likes" from friends in social media (Rosenthal-von der Pütten, 2019). There is a wealth of research-based information for teachers on how to implement feedback efficiently (Hattie \& Timperley, 2007), at least in face-to-face situations, but less is known about technology-enhanced feedback. Therefore, in this study the self-reported technology-enhanced feedback notes of pupils around the age of $16(\mathrm{~N}=2031)$ in basic education were used as they reveal the kind of feedback they experienced receiving. The data were analyzed using latent profile analysis (LPA) to find out whether receiving feedback according to different patterns is connected with indicators of learning and well-being. It is expected that LPA and further analysis will reveal individual differences in pupils' perceptions. These are essential for enhancing understanding when pedagogically appropriate technology-enhanced feedback is being designed.

\section{Technology-enhanced Feedback}

Feedback is either internally or externally received information about the gap between the current level of knowledge and understanding related to desired goals (Hattie \& Timperley, 2007). This study focuses on technology-enhanced feedback from teacher to pupils and examines whether this external feedback can support learning and academic well-being, as suggested in the Core Curriculum. In Finnish basic education, almost all teachers use an online application where they can choose from among predefined options the kind of feedback that they want to give pupils related to their learning and behavior during lessons. In international markets, there are several commercial online gradebooks or educational platforms that deliver automated text messages or report cards from teachers to parents and pupils (Bergman \& Chan, 2017; Doss, Fahle, Loeb, \& York, 2017), which have resulted in public discussion about the pedagogically appropriate use of these tools (Heimo et al., 2015; Hoffman, 2008; Kuusimäki, Uusitalo-Malmivaara, \& Tirri, 2019). Despite criticism, ElShaer and colleagues (2019) recently reported that the majority of university students prefer technology-enhanced feedback to feedback delivered face-to-face, as they perceive it as useful for learning.

Although encouraging feedback to support motivation is mainly recommended (Hattie \& Timperley, 2007; Ryan \& Deci, 2000a), some platforms still deliver only negative information about missing assignments or failed exams (Bergman \& Chan, 2017). A recent study about technology-enhanced feedback showed that boys and pupils with special needs are more likely to be on the receiving end of criticism related to behavior instead of encouragement (Oinas et al., 2018), which would be more effective (Hughes, 2010; Reeve et al., 2009). Surveying pupils' perceptions is important, as Cutumisu (2019) recently found that an adopted mindset moderates taking advantage of technology-enhanced feedback. Jeno and colleagues (2017) found that technology-enhanced feedback improved learning and well-being when feedback was related to 
competence. Tempelaar, Rienties, Mittelmeier and Nguyen (2018) concluded that learning analytics and profiling help to identify learners needing support and to tailor efficient technology-enhanced feedback.

\section{Feedback and Learning}

Feedback needs to be accepted and reflected on in order to support learning (Hattie \& Timperley, 2007; Wiliam, 2011). In other words, a pupil should be motivated to seek and take advantage of feedback (Cutumisu et al., 2019; Elliot \& Dweck, 2005). "To be motivated means to be moved to do something (Ryan \& Deci, 2000 b, p. 54)", duly pointing to an inner effort for learning (Elliot \& Dweck, 2005). Motivation varies between levels of intrinsic or extrinsic motivation depending on the reasons for acting toward achieving a desired goal, and both are beneficial for learning (Deci \& Ryan, 1985; Ryan \& Stiller, 1991). Usually, intrinsic motivation declines and shifts to extrinsic motivation during the school years, with perceived competence being the best predictor of motivation (Elliot \& Dweck, 2005; Harter, 2012). However, in optimal circumstances, interest toward a deeper level of understanding may increase (Renninger \& Hidi, 2011).

Hattie and Timperley (2007) suggest that feedback encouraging pupils to trust themselves and make an effort to progress in a task supports motivation. Feedback should always be targeted toward the learning process, as person-targeted feedback has a negative effect on learning, even if it is positive in terms of content (Hattie \& Timperley, 2007; Wiliam, 2011). Pekrun and colleagues (2014) observed that anticipating feedback resulted in better performance, indicating that learners expended more effort and appreciated receiving feedback. Findings suggest that using technology in education is beneficial for learners' motivation and achievements (Gambari, Gbodi, Olakanmi, \& Abalaka, 2016).

\section{Feedback and Academic Well-being}

Competence, which is at the core of motivation and academic well-being, is a need to experience oneself as effective in relation to the learning environment (Elliot \& Dweck, 2005; Wang \& Peck, 2013). Teachers' emotional support is one of the key elements of positive classroom interaction and has been shown to be associated with higher cognitive performance and pleasant affective experiences among pupils (Ruzek, Hafen, Allen, Gregory, Mikami, \& Pianta, 2016; Ryan, Stiller, \& Lynch, 1994). Negative feedback usually decreases the sense of competence and detracts from the teacher-pupil relationship (Griffin, 2018), while a trusting and warm relationship with the teacher may make it easier to handle criticism (Skinner \& Edge, 2002). Moreover, perceptions of teachers' unsupportiveness is related to pupils' lower performance and disengagement, leading to negative interactions (Gasser, Grütter, Buholzer, \& Wettstein, 2018).

Although the teacher-student relationship impacts academic outcomes and pupils' perceived well-being at school, there is no clear evidence of the causality of these factors (Wentzel, 2009). Individual differences and previous learning experiences regulate how the surrounding environment and feedback is interpreted (Kluger \& DeNisi, 1996). Rawlings, Tapola and Niemivirta (2017) point out the importance of teachers' awareness of innate individual differences in their pupils, and reported that sensitivity to punishments and rewards in social settings may be connected to adopted learning goals. Hagger, Koch and Chatzisarantis (2015) noticed that people who are sensitive to social norms and those who are unaffected by the opinions of others benefit from positive feedback, as it supports their competence during a task. They conclude that despite individual differences, intrinsic motivation can be supported through positive feedback (Hagger et al., 2015). Schenke and colleagues (2018) concluded that teachers engage in different feedback practices with different pupils.

Leary and Terry (2012) argue that when feedback comes from another person, the experience always includes interpersonal dimensions. At school, the power structure between teacher and pupil adds its own dimension when feedback is delivered (Cochran et al., 2017). Compared to other countries, school engagement in lower secondary school is relatively low in Finland, possibly indicating problematic relationships with teachers. By clustering the PISA data, Linnakylä and Malin (2008) found that while some pupils are highly engaged, almost one-third perceived teachers as unsupportive and school as less important, and hence it is worth studying whether technology-enhanced feedback is connected to the relationship with teachers. Furthermore, it has been observed that in Finland, relationships with teachers at school are 
stronger predictors of academic well-being than parental support (Lindfors, Minkkinen, Rimpelä, \& Hotulainen, 2017).

Thus, academic well-being in this study relates to the affective factors connected to situations whereby technology-enhanced feedback is provided at school. The general aim of feedback is to improve learning but the form of the feedback and/or its absence may also have unwanted effects in respect of pupils' well-being and motivation (Wang \& Peck, 2013). For example, the timing, when feedback is given (or not given), why feedback is given, and how it is delivered by a significant adult are all factors likely to affect interpersonal dimensions, such as the teacher-pupil relationship and the pupil's perceived competence.

\section{Research Questions}

Although an extensive body of literature suggests encouraging feedback to support learning (e.g. Hattie \& Timperley 2007; Hughes, 2010), recent findings about technology-enhanced feedback provide evidence of negative feedback and unequal technology-enhanced feedback practices by teachers (Kuusimäki et al., 2019; Oinas et al., 2017, 2018). Pekrun and colleagues (2014) conclude that feedback mediates both cognitive and affective factors and, therefore, connections between learning and academic well-being and technologyenhanced feedback are studied using LPA. As functioning interpersonal relationships are important for pleasant experiences at school, pupils' perceived relationship with their teacher is considered the first component of academic well-being. Secondly, a pupil's perception of his or her competence as a learner is used as another indicator of academic well-being (see Korhonen, Linnanmäki, \& Aunio, 2014). Intrinsic and extrinsic motivation and school achievements are duly used to evaluate their learning. In this vein, the research questions to be addressed are:

1. Based on self-reported technology-enhanced feedback received from teachers, what kind of profiles can be identified?

2. Are pupils belonging to the identified profiles different regarding their perceptions of learning and academic well-being?

\section{METHODS}

The data for this study were collected as part of a national learning-to-learn assessment of ninth-graders in May 2017. Originally, 2,969 pupils were randomly selected from 33 Finnish-speaking schools and 28 municipalities to provide nationally representative data. A total of 2,031 pupils (68.4\%) around 16 years of age (girls 50.2\%) from 31 schools, 28 municipalities and 33 class groups completed an online questionnaire for assessment purposes. Finnish and Swedish are both official languages in Finland and around $94 \%$ of participants in this study reported that they speak Finnish at home with their parents. The rest reported speaking languages such as English, Russian, or Chinese with their parents.

\section{Measures}

The online platform for providing technology-enhanced feedback examined in this study has been in use for over 15 years and it is therefore possible that these pupils have received feedback in this form since the first grade. To evaluate received technology-enhanced feedback from teachers, we first enquired whether the pupils were familiar with the online platform in question, and whether they had received technologyenhanced feedback. We subsequently asked the pupils to evaluate how often they had received feedback related to praise, forgotten matters or behavior problems, using separate questions for each (1=never, $2=1$ 5 times per school year, 3=around once a month, 4=around once a week, 5=several times a week). These feedback categories were defined earlier based on original feedback notes exported directly from the feedback platform (Oinas et al., 2017). The importance of feedback from teachers was measured using a 7point Likert scale with two items: Teachers' feedback is important for learning and It is important for me to obtain encouraging feedback from teachers. 
Table 1. Factor scores and reliability of the measured items related to learning and well-being

\begin{tabular}{|c|c|c|c|c|}
\hline & $\begin{array}{c}\text { Intrinsic } \\
\text { motivation } \\
\alpha .849 \\
\end{array}$ & $\begin{array}{c}\text { Extrinsic } \\
\text { motivation } \\
\alpha .908 \\
\end{array}$ & $\begin{array}{c}\text { Competence } \\
\alpha .887\end{array}$ & $\begin{array}{c}\text { Relationship with } \\
\text { teachers } \\
\alpha .902 \\
\end{array}$ \\
\hline My goal is to obtain information. & $-.860^{*}$ & & & \\
\hline Learning new things is important for me in school. & $-.794^{*}$ & & & \\
\hline My goal is to succeed well in school. & & .871 & & \\
\hline It is important to perform well in school. & & .741 & & \\
\hline It is important to get good grades. & & .759 & & \\
\hline I am competent enough to do well in school. & & & $\because .954$ & \\
\hline I am competent enough to succeed in school. & & & -.799 & \\
\hline I am clever and have abilities as a pupil. & & & -.637 & \\
\hline I feel that teachers consider and appreciate pupils' ideas. & & & & .824 \\
\hline I feel that I'm respected by teachers. & & & & .785 \\
\hline I consider teachers to be fair and just. & & & & .839 \\
\hline I feel that teachers accept me the way I am. & & & & .774 \\
\hline I usually get along with the teachers very well. & & & & .730 \\
\hline
\end{tabular}

Connections between technology-enhanced feedback and learning-related motivation (intrinsic and extrinsic), competence and relationship with the teacher were measured with 14 items (see Table 1) belonging to the longer questionnaire designed for an ongoing longitudinal study within the learning- tolearn framework of the Centre for Educational Assessment, which is well established in nationally representative educational studies (Hautamäki \& Kupiainen, 2014; Niemivirta, 2004). Exploratory factor analysis was used to evaluate the latent structure of the chosen items using the Maximum Likelihood method and Direct Oblimin as a rotation (Table 1). The five-factor solution that was chosen explained $79 \%$ of the variance $\left(x^{2}(d f)=214.057(61), p=.000\right)$. One item measuring motivation cross-loaded weakly for both intrinsic and extrinsic motivation and was therefore excluded.

School achievement was computed using grades for mathematics, mother tongue, history and chemistry obtained directly from school administrators. In Finland, school grades range between 4 and 10, and girls typically have better school achievements than boys. The achievement average in this sample was 8.01 .

\section{Data Analyses}

Descriptive statistics were observed to begin with to gain overall knowledge about the data (Table 2). Maximum likelihood estimation was used to ensure that most differences could be explained at the individual level rather than at the school or class levels. As individual differences explained around $89 \%$ of the variance and as a pupil may receive several types of feedback at the same time, we performed latent profile analysis (LPA) with MPlus software to identify different patterns of received feedback. LPA is a method that is used to observe differences at the individual level, rather than observing the variable means. We chose LPA over clustering as a more flexible grouping analysis (Oberski, 2016). The number of profiles was defined by comparing fit indices (Marsh, Lütdke, Trautwein \& Morin, 2009; Nylund, Asparouhov \& Muthén, 2007; UCLA, 2019; Williams \& Kibowski, 2016) such as the Bayesian information criterion (BIC), the Vuong-Lo-MendellRubin likelihood ratio test (VLMR), the Lo-Mendell-Rubin adjusted test (LRT; Lo, Mendell \& Rubin, 2001), and the bootstrap likelihood ratio test (BLRT), which was shown to be optimal for assessing the number of latent classes (Finch, 2015). Furthermore, an entropy value and individual posterior probabilities were evaluated to determine the best model fit. The first profile in LPA was fixed to value 1 (Kreuter \& Muthén, 2008), in order to identify pupils who reported never receiving technology-enhanced feedback.

The idea of LPA is to reveal homogenous subsets, in this case based on received technology-enhanced feedback, usually different by sizes. To study the differences between technology-enhanced feedback profiles according to learning and well-being, a MANOVA was performed between intrinsic and extrinsic motivation, competence, relationship with teachers, school achievements, importance of feedback and identified profiles. As profiles are likely to be different in terms of numerus, it was assumed that the assumption of equal variance matrixes would probably be violated when conducting further analysis. Thus, the reader must be aware that the reported significant differences found with MANOVA may not be 
Table 2. Descriptive statistics and distribution of the received technology-enhanced feedback notes

\begin{tabular}{lccc}
\hline \multicolumn{4}{c}{ Evaluate how often you have received technology-enhanced feedback related to: } \\
\hline & Teacher praise (N=1877) & Forgotten matters (N=1866) & Behavior problems (N=1870) \\
\hline & M 3.22, SD 1.17 & M 2.34, SD 1.12 & M 1.78, SD 1.03 \\
1=never & $8.5 \%$ & $23.2 \%$ & $48.7 \%$ \\
2=1-5 times a year & $17.2 \%$ & $34.3 \%$ & $25 \%$ \\
3=around once a month & $24.6 \%$ & $19.4 \%$ & $11.1 \%$ \\
4=around once a week & $29.5 \%$ & $10.3 \%$ & $4.4 \%$ \\
5=several times a week & $12.5 \%$ & $4.7 \%$ & $2.8 \%$ \\
missing & $7.6 \%$ & $8.2 \%$ & $8 \%$ \\
Total & $100 \%$ & $100 \%$ & $100 \%$ \\
\hline
\end{tabular}

completely reliable with the current data. In order to avoid violating the assumption of multivariate normality, which is often a case in behavioral sciences (Bathke et al., 2018), we examined outliers based on the test for Mahalanobis distance. Furthermore, the homogeneity of variance and Box's $M$ test were observed. Wilk's Lambda was used to analyze the main effects of the variables and Tukey was used to detect homogenous subsets based on observed means. The results of post-hoc-tests were compared with GamesHowell-tests. Effect sizes of the group comparisons are interpreted according to Cohen's d: .1 - .49 small effect, .5 - .79 medium effect, and higher than .80 large effect (Lenhard \& Lenhard, 2016).

\section{RESULTS}

According to the pupils' self-rated evaluation, a specific online platform was used in $97.4 \%$ of schools to provide technology-enhanced feedback, and $95.9 \%$ of pupils responded that they had received feedback from teachers via computer or smartphone. However, further analysis revealed that in each school, the majority of pupils reported that the platform is used but, for some reason, there were also pupils who reported the opposite. Descriptive statistics showed a large variation between received feedback according to different content (Table 2). There were pupils who received teacher praise several times a week, as well as pupils who reported that they had never received encouraging feedback. Questions related to forgotten matters (such as forgotten homework or books) and behavior problems (inappropriate behavior or language during the lesson for example) revealed a similar situation. On average, almost all students reported receiving technology-enhanced feedback, but the average frequencies indicated that this was a monthly occurrence. Almost half of the pupils reported that they had never received feedback related to behavior problems, resulting in a very low mean value.

There was also variation in the school- and class-level differences. Variance between school and class components showed that between the variables Teacher praise (school 15.2\%, class 5.2\%), Forgotten matters (school 2.3\%, class 2.9\%), Behavior problems (school 3.1\%, class 5.2\%) and No feedback (school 6\%, class $2.6 \%)$ some of the variance was explained.

\section{Technology-enhanced Feedback Profiles}

In order to address the first research question, latent profile analysis (LPA) was conducted using variables measuring feedback related to Teacher praise, Forgotten matters and Behavior problems. Models from a oneclass solution to nine classes were observed to determine the number of profiles best describing the data. Large sample sizes are likely to result in more profiles than small samples, and therefore in LPA it is important to observe both qualitative and quantitative differences between profiles (Marsh et al., 2009). The fit indices are presented in Table 3.

Finch (2015) argues that AIC in particular is likely to propose more profiles than actually exist, and hence BIC was trusted to observe the best solution. The value for the criterion improved until the seven-profile solution and then began to worsen, indicating that the seven-profile solution best represented the data. VLMR and LMR tests comparing the model with K profiles to a model with K-1 profiles (Tofighi \& Enders, 2007; UCLA, $2019)$ did not yield a significant result, but supported the seven-profile solution, and the bootstrap test $(p=.000)$ confirmed the result. 
Table 3. Fit indices for LPA

\begin{tabular}{cccll}
\hline Number of profiles & BIC & Entropy & VLMR & Posterior probabilities \\
\hline 2 & 16255.038 & 1.000 & & $.000,1.000$ \\
3 & 15668.659 & .948 & .915 & $.000, .996, .940$ \\
4 & 15272.023 & .911 & .284 & $.658, .985, .994 ., 957$ \\
5 & 13030.271 & .941 & .348 & $.670,1.000, .956, .993, .1 .000$ \\
6 & 12992.223 & .927 & .265 & $.686,1.000,1.000, .774, .936, .991$ \\
$7^{*}$ & 12933.200 & .902 & .229 & $.728, .925, .1 .000, .884, .937, .930, .990$ \\
8 & 12935.064 & .893 & .999 & $.788, .968, .919, .993, .913, .931,683, .916$ \\
9 & 12987.953 & .899 & .999 & $.739, .906,1.000, .686, .000, .926, .896, .996, .896$ \\
\hline
\end{tabular}

* Seven profiles were identified as being most representative of the data.

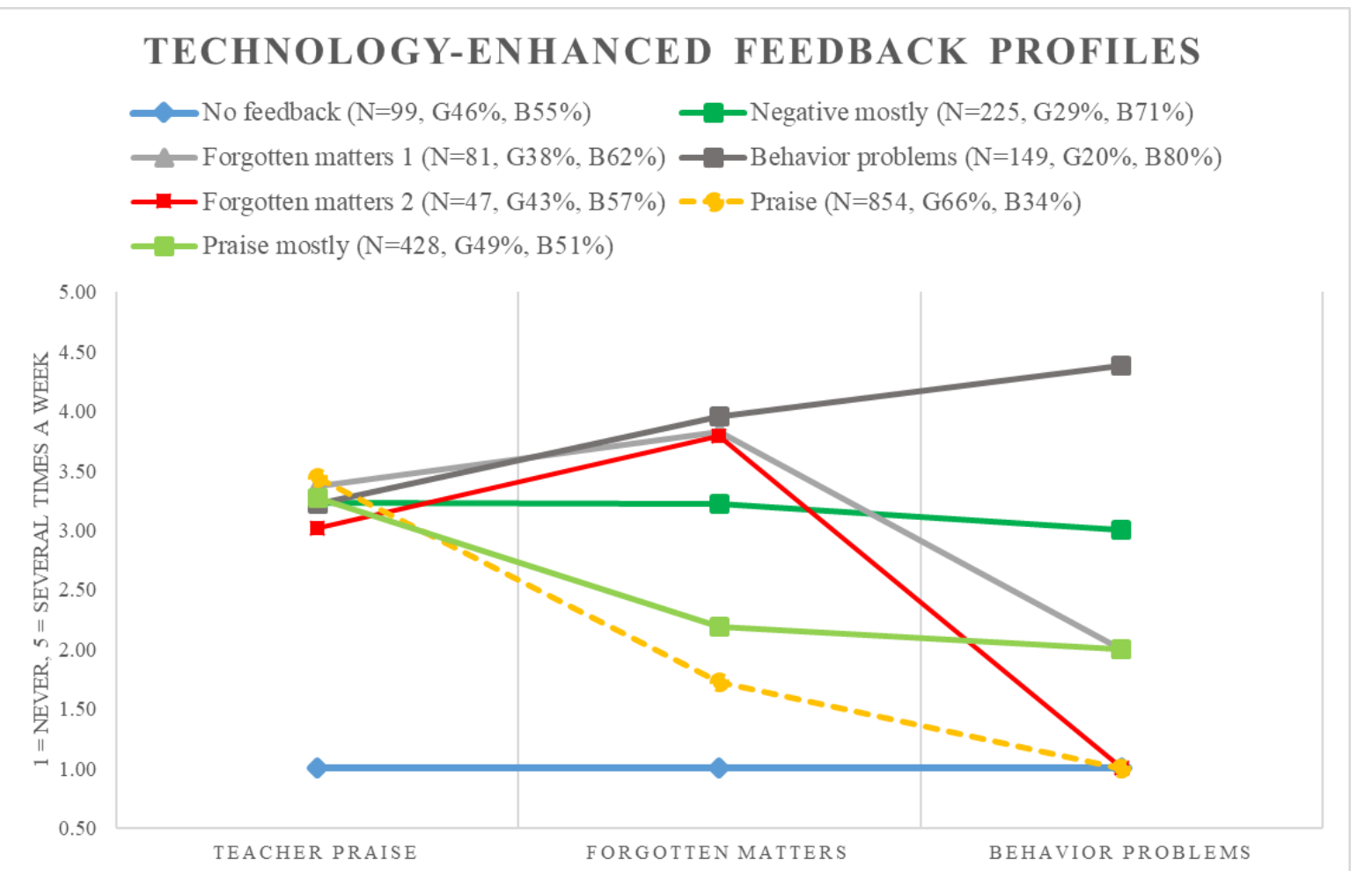

Figure 1. Technology-enhanced feedback profiles. Boys were over-represented in each profile, except for the largest profile for pupils receiving mainly teacher praise (yellow broken line)

\section{Associations between Identified Profiles and Dependent Variables}

The aim of RQ2 was to evaluate whether there were differences in average mean values between identified profiles and variables measuring learning and well-being. The MANOVA with the identified profiles as independent variables and intrinsic and extrinsic motivation, competence, relationship with teachers, school achievements and importance of feedback as dependent variables indicated a significant multivariate effect, with Wilks' Lambda yielding $.735, F(36)=15.589, p<.001, n^{2}=.05$. Statistically significant differences were found concerning intrinsic motivation $\left(F(6)=32.832, p<.001, n^{2}=.10\right)$, extrinsic motivation $(F(6)=50.107$, $\left.p<.001, n^{2}=.10\right)$, competence $\left(F(6)=26.019, p<.001, n^{2}=.08\right)$, relationship with teachers $(F(6)=45.229, p<.001$, $\left.n^{2}=.13\right)$, school achievements $\left(F(6)=52.010, p<.001, n^{2}=.09\right)$, and importance of feedback $(F(6)=28.105$, $p<.001, n^{2}=.15$ ) between the groups shown in Figure 2. Descriptive statistics and homogenous subsets are displayed in Table 4. 


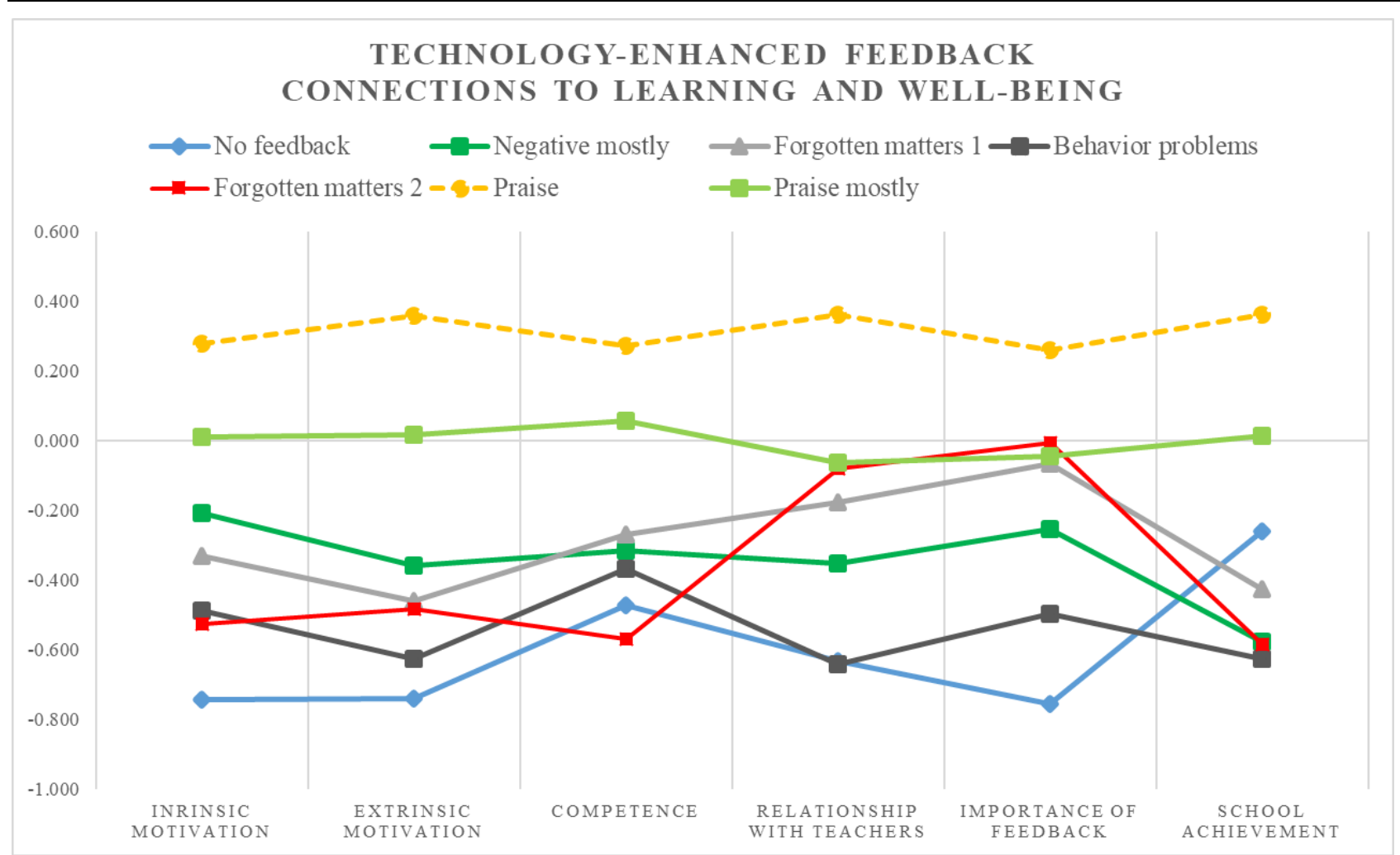

Figure 2. Connections between technology-enhanced feedback profiles and scales measuring learning and well-being of pupils

Although the mean values of profiles according to the scales were quite close to each other, standard deviations showed that there were large individual variances in each latent construct (see Table 4). In addition, the analysis revealed a consistent association between technology-enhanced feedback, learning and academic well-being; the more pupils were praised, the higher they rated their motivation, competence and relationship with teachers, particularly when compared with pupils who did not receive feedback (Figure 2). It is also worth noting that the standard deviations for profiles receiving mainly praise were smaller than for those receiving no feedback. This means that in profiles receiving no feedback or a lot of negative feedback, there were pupils who rated their values as relatively low. A divergence in profiles receiving mainly praise compared to profiles receiving more negative feedback or no feedback was also seen based on homogeneous subsets, as praised profiles differed statistically from others (see Table 4). While the most systematic and statistically significant differences existed between profiles receiving Praise and No feedback we calculated effect sizes of these pairwise comparisons. These showed that there were large effect in terms of intrinsic $(d=1.059)$ and extrinsic motivation ( $d=1.201)$, relationship with teacher $(d=1.132)$ and importance of feedback ( $d=1.069)$. Moreover, there were medium effects in perceived competence $(d=.707)$ and school achievements ( $\mathrm{d}=.502)$, and they all favored Praise group over the No feedback group, respectively. The identified profiles are described and named below according to the content of the received feedback. 
Table 4. Means and standard deviations between technology-enhanced feedback profiles and scales measuring learning and well-being of pupils

\begin{tabular}{lcccccc}
\hline & $\begin{array}{c}\text { Intrinsic motivation } \\
\text { (SD) }\end{array}$ & $\begin{array}{c}\text { Extrinsic } \\
\text { motivation (SD) }\end{array}$ & $\begin{array}{c}\text { Competence } \\
\text { (SD) }\end{array}$ & $\begin{array}{c}\text { Relationship } \\
\text { with teachers } \\
\text { (SD) }\end{array}$ & $\begin{array}{c}\text { Importance of } \\
\text { feedback (SD) }\end{array}$ & $\begin{array}{c}\text { School } \\
\text { achievement } \\
\text { (SD) }\end{array}$ \\
\hline Praise & $5.21(1.14) \mathrm{a}$ & $5.69(1.14) \mathrm{a}$ & $5.72(1.11) \mathrm{a}$ & $5.37(.99) \mathrm{a}$ & $5.19(1.30)$ & $8.41(1.30)$ \\
Praise mostly & $4.87(1.09) \mathrm{a}, \mathrm{b}$ & $5.22(1.20) \mathrm{a}, \mathrm{b}$ & $5.44(1.18) \mathrm{a}, \mathrm{b}$ & $4.84(1.20) \mathrm{b}$ & $4.76(1.35)$ & $4.76(1.35)$ \\
Negative mostly & $4.60(1.09) \mathrm{b}, \mathrm{c}$ & $4.74(1.06) \mathrm{b}, \mathrm{c}$ & $4.97(1.12) \mathrm{c}$ & $4.45(1.15) \mathrm{b}, \mathrm{c}$ & $4.49(1.23)$ & $7.37(1.23)$ \\
Forgotten matters 1 & $4.49(1.13) \mathrm{b}, \mathrm{c}$ & $4.64(1.27) \mathrm{c}, \mathrm{d}$ & $5.07(1.27) \mathrm{b}, \mathrm{c}$ & $4.72(1.16) \mathrm{b}$ & $4.75(1.38)$ & $7.53(1.38)$ \\
Behavior problems & $4.24(1.28) \mathrm{c}, \mathrm{d}$ & $4.36(1.44) \mathrm{c}, \mathrm{d}$ & $4.91(1.24) \mathrm{c}$ & $4.12(1.40) \mathrm{c}$ & $4.22(1.54)$ & $7.27(1.54)$ \\
Forgotten matters 2 & $4.22(1.37) \mathrm{c}, \mathrm{d}$ & $4.57(1.34) \mathrm{c}, \mathrm{d}$ & $4.66(1.43) \mathrm{c}$ & $4.85(1.30) \mathrm{b}$ & $4.73(1.55)$ & $7.27(1.55)$ \\
No feedback & $3.90(1.88) \mathrm{d}$ & $4.18(2.01) \mathrm{d}$ & $4.78(1.82) \mathrm{c}$ & $4.14(1.71) \mathrm{c}$ & $3.68(2.16)$ & $7.70(2.16)$ \\
\hline
\end{tabular}

Note 1: The scale for school achievement varies between 4 and 10 in Finland. Other scales are measured with a 7-point Likert scale. Note 2: Homogeneous subsets are represented by letters a-d.

Note 3: Based on the test for multivariate normality (Bathke et al., 2018) we first excluded 29 participants as outliers, although, they represented an important information of pupils belonging mainly in profile of no feedback. As there were no significant differences with the results of the whole data compared to findings with shortened data, we decided to use data without exclusion.

\section{Pupils praised by teachers}

Based on pupils' self-reported technology-enhanced feedback received from their teacher, as many as $80 \%$ of girls, and $55 \%$ of boys belonged to profiles characterized by receiving teacher praise approximately more than once a month, and feedback related to forgotten matters or behavior problems only 1-5 times a year. As these pupils reported receiving mainly positive feedback, these profiles were termed Praise and Praise mostly. Results indicate that the more pupils received encouraging feedback, teacher praise, the higher they rated their motivation, competence, relationship with teachers and the importance of feedback. The school achievements of praised pupils were also higher compared to pupils in other profiles.

\section{Pupils with feedback concerning forgotten matters}

Next, we identified profiles in which $5 \%$ of girls and $9 \%$ of boys (Forgotten matters $1 \& 2$ ) received feedback about forgotten matters approximately once a week, but also teacher praise every now and then. Compared to Forgotten matters 2, the pupils in the profile Forgotten matters 1 also received some feedback related to behavior problems. Pupils in these profiles rated their motivation and competence as relatively low, but their relationship with teachers and the importance of feedback as relatively high. On average, the achievements of these pupils were among the lowest in the sample.

\section{Pupils with mostly negative feedback}

Around $10 \%$ of girls and $30 \%$ of boys belonged to profiles termed Negative mostly and Behavior problems, as they received a lot of negative feedback and feedback about their behavior several times a week. Despite the negative feedback, these pupils also reported receiving praise, perhaps as a result of teachers attempting to compensate for negative remarks. Pupils rated scales measuring learning and well-being relatively low, and the achievements of these pupils were correspondingly among the lowest.

\section{Pupils with no feedback}

There was also a profile for pupils (girls $5 \%$, boys $6 \%$ ) who reported that they had never received any technology-enhanced feedback. It is understandable that pupils receiving no feedback rated the importance of feedback lowest. Furthermore, although assumptions of causality cannot be shown, it seems that, paradoxically, pupils who did not receive technology-enhanced feedback suffered from the feedback practices the most, as they rated their motivation and relationship with teachers lowest. Standard deviation of the means of the scales was large in this profile, revealing that there were pupils whose learning and academic well-being needed attention. 


\section{DISCUSSION}

School is first and foremost a place for learning skills and acquiring knowledge for the future. Besides learning, school also influences pupils' quality of life (Pekrun, 2009; Ryan \& Stiller, 1991) by providing valuable experiences and relationships between peers and adults. Similarly, while the purpose of feedback in the first instance is to provide information to support learning (Hattie \& Timperley, 2007), it also impacts teacherpupil interaction (Harter, 2012) and self-perceptions (Pekrun, 2009) for example. Currently, technologyenhanced feedback is provided by clicking predefined options via numerous, commercial online applications and, therefore, it is important to evaluate the influence of this feedback on learning and the academic wellbeing of pupils. This was carried out by analyzing a nationally representative sample of 2,031 16-year-old pupils in Finnish basic education. Latent profile analysis was conducted to begin with in order to identify individual patterns of received technology-enhanced feedback, followed by MANOVA to observe differences between identified profiles and scales indicating learning and academic well-being.

Although the majority of pupils reported receiving technology-enhanced feedback, there were also pupils who did not receive any feedback; teacher praise, feedback about behavior problems or forgotten matters such as books or homework. A total of seven profiles were identified in terms of technology-enhanced feedback, and connections between these profiles and motivation, school achievement, competence and relationship with teachers were found. According to the data, pupils receiving mainly encouraging feedback reported the highest values indicating feedback as being beneficial for them. Paradoxically, pupils who did not receive technology-enhanced feedback at all, showed to have the lowest values in the same measures regardless their relatively high school achievements. The current results provide valuable evidence that differences do exist among the learning and academic well-being indicators for pupils who received technology-enhanced feedback with different patterns.

\section{Technology-enhanced Feedback Connections to Learning and Academic Well-being}

Process targeted encouraging (Hattie \& Timperley, 2007) and anticipated feedback (Pekrun et al., 2014) enhance performance. The results from this study support both of these assumptions, indicating that technology-enhanced teacher praise is beneficial to learning, as pupils who received a lot of praise reported the highest values in all measured scales. Furthermore, the pupils who received both positive and negative feedback rated their motivation higher than those who did not get any feedback. Although intrinsic motivation is shown to shift to extrinsic motivation during the school years (Harter, 2012), these data reveal that most pupils had maintained their intrinsic motivation. These pupils belonged to the profiles that received mostly praise. It could be the case that feedback from the teacher increases meaningfulness, which in turn facilitates circumstances whereby the usual diminishing of interest does not exist (Renninger \& Hidi, 2011). Pupils who are not intrinsically motivated may be willing to learn out of respect for significant others and for those to whom they perceive they are related (Ryan \& Deci, 2000a), and therefore the relationship with the teacher is essential for learning.

Observing the self-rated values of this sample showed that most pupils perceived their relationship with school, teachers and learning quite positively. Still, standard deviations of the scales revealed pupils whose lower motivation and experiences are a cause for concern, as according to Ryan and Deci (2000a), all psychological needs, such as competence and functioning interpersonal relationships, have to be satisfied to foster well-being. Despite the lack of causality between the received feedback and pupils' perceptions, it is notable that perceived intrinsic motivation and the relationship with teachers were weakest for pupils receiving negative feedback or no feedback at all when considering the effect sizes. Therefore, this study supports the earlier findings that not all pupils perceive themselves as being treated similarly at school (Linnakylä \& Malin, 2008), and school plays an important role in building academic well-being (Lindfors et al., 2017).

Feedback from significant adults shapes the self-concept of growing children and adolescents, while discordant feedback arouses confusion (Harter, 2012; Harter et al., 1998). Receiving dozens of negative feedback notes during the school years, when a child is at the most vulnerable age for creating a healthy selfconcept (Harter, 2012), may result in a situation in which adolescents start to ignore feedback, with adults at 
school becoming insignificant and school unimportant. Hagger and colleagues (2015) noticed that positive feedback was valuable for those who were sensitive to social norms, but also for pupils who were more independent. The findings by Hagger and colleagues indicate the importance of encouraging feedback practices for all pupils equally. If supportive conditions are crucial even for intrinsically-motivated and welladjusted pupils (Ryan \& Deci, 2000b), then how about pupils with low motivation? According to the current results, less motivated pupils received less encouraging feedback, indicating that they are likely to suffer unsupportive conditions. Ryan and colleagues (1994) were particularly worried about a small group of boys being isolated from adults both at school and at home. Current results partly supported this finding by showing that there were more boys than girls who received negative attention as a form of technologyenhanced feedback. It should be studied whether technology-enhanced feedback is perceived as social acceptance from a teacher or is even comparable to "likes" in social media in the minds of pupils (Heimo et al., 2015; Rosenthal-von der Pütten, 2019).

It is evident that several matters affect the kind of feedback a pupil receives; it may be that a pupil is strongly motivated and thus praised by teachers, or experiences challenges at school resulting in feedback about forgotten matters or behavior problems. According to Ryan and colleagues (1994), affluent pupils with supportive parents trust teachers and are well-adjusted at school, and hence receive positive attention from teachers, which increases their relationships with other adults and hence their motivation even further. Similarly, Schenke and colleagues (2018) hypothesize that positive teacher-student interaction is bidirectional. In this study, the weak relationship with teachers experienced by those who did not receive any feedback at all may indicate that these pupils perceive themselves as being overlooked by teachers.

\section{Limitations}

Originally, the questionnaire used in this study had been created to measure learning to learn (Hautamäki \& Kupiainen, 2014), and was therefore not ideal for studying the connection between technology-enhanced feedback and learning and the academic well-being of pupils. As assessing learning to learn is difficult and time-consuming for pupils, we added only five questions based on earlier findings about technologyenhanced feedback. Hence, this study is only the first step in revealing phenomena worth considering for further research. For example, qualitative interviews about technology-enhanced feedback could shed considerable light on this phenomenon.

Seven profiles of received technology-enhanced feedback were identified in this study. It should be kept in mind that the number of profiles discovered depends on the data at hand (Marsh et al., 2009), and therefore, the results may vary with different data. Although the number of profiles varies, it seems that differently distributed profiles can be detected, indicating that pupils receive technology-enhanced feedback unequally and, more importantly, that technology-enhanced feedback is associated with the learning and academic well-being of pupils. Thus, the current results support the earlier findings (Oinas et al., 2018). Data were collected by asking pupils to self-rate the technology-enhanced feedback they had received, and therefore it should be borne in mind that the reported amount and quality of feedback may not be completely accurate.

\section{Conclusions}

The data collection for this study was completed during the final month of the participants' nine-year compulsory education. It is possible that the pupils in this sample had received technology-enhanced feedback throughout their years at school, as this application has been in use for over 15 years in Finland. Teachers' feedback practices in relation to this platform have been the subject of widespread public discussion during these years (Heimo et al., 2015), and hence pupils are familiar with the fact that some of their peers receive a great deal of teacher attention via technology-enhanced feedback. In light of these results, it seems that technology-enhanced feedback is the most harmful for those pupils who did not receive any at all. In particular, motivation and the relationship with teachers were weak for those pupils who did not receive technology-enhanced feedback, although their school achievements were high. We should ask therefore whether these pupils feel ignored by their teachers. Nevertheless, this study also indicates teachers' efforts to provide encouraging feedback for most pupils, even those displaying problematic 
behavior. It was not surprising that praise cumulated to pupils who reported highest values in motivation, perceived competence and relationship with teachers. These results indicate that perhaps pupils who already are motivated to show their best in school receive teacher praise, although others may benefit teacher attention also. As this study cannot provide causal evidence, it should be studied whether learning and academic well-being of pupils can be supported by providing equally encouraging technology-enhanced feedback.

The results of this study are important for two reasons. First, they show that theoretical knowledge about effective feedback is not fully utilized in relation to current technology-enhanced practices. Therefore, in order to avoid any harmful effects of technology-enhanced feedback, pedagogically appropriate applications should be created and clear guidance should be provided about their use. Secondly, this study shows that observing technology-enhanced feedback critically is relevant if we put a high value on the overall well-being of pupils as a starting point for learning.

\section{ACKNOWLEDGEMENTS}

This study was funded by the University of Helsinki, Finland.

\section{REFERENCES}

Bathke, A.C., Friedrich, S., Pauly, M., Konietschke, F., Staffen, W., Strobl, N., \& Höller, Y. (2018). Testing mean differences among groups: multivariate and repeated measures analysis with minimal assumptions. Multivariate Behavioral Research, 53(3), 348-359. https://doi.org/10.1080/00273171.2018.1446320

Bergman, P., \& Chan, E.W. (2017). Leveraging parents: The impact of high-frequency information on student achievement. AERA conference-paper, 1-59. Retrieved from http://www.columbia.edu/ psb2101/ ParentRCT.pdf

Cochran, K. F., Reinsvold, L. A., \& Hess, C. A. (2017). Giving students the power to engage with learning. Research in Science Education, 47, 1379-1401.

Corno, L. (2009). Work habits and self-regulated learning: Helping students to find "will" from a "why". In D. H. Shunck \& B. J. Zimmerman (Eds.) Motivation and self-regulated learning, theory, research and applications (pp. 197-222). Routledge.

Cutumisu, M., Chin, D. B., \& Schwartz, D. L. (2019). A digital game-based assessment of middle-school and college students' choices to seek critical feedback and to revise. British Journal of Educational Technology, 50(6), 2977-3003. https://doi.org/10.1111/bjet.12796

Cutumisu, M. (2019). The association between feedback-seeking and performance is moderated by growth mindset in digital assessment game. Computers in Human Behavior, 93, 267-278.

Deci, E. L., \& Ryan, R. M. (1985). Intrinsic motivation and self-determination in human behavior. Plenum.

Doss, C., Fahle, E., Loeb, S., \& York, B. (2017). Supporting parenting through differentiated and personalized text-messaging: testing effects on learning during kindergarten. Working Paper No.16-18. Retrieved from http://cepa.stanford.edu/wp16-18

Elliot, A. J., \& Dweck, C. S. (2005). Competence and motivation: Competence as the core of achievement motivation. In A. J. Elliot \& C. S. Dweck (Eds.), Handbook of competence and motivation (pp. 3-12). New York, NY: Guilford.

ElShaer, A., Casanova, D., Freestone, N. S., \& Calabrese, G. (2019). Students' perceptions of the value of electronic feedback - does disciplinary background really matter? British Journal of Educational Technology, 1-17. https://doi.org/10.1111/bjet.12881 
Finch, H. (2015). A comparison of statistics for assessing model invariance in latent class analysis. Open Journal of Statistic, 5, 191-210. https://doi.org/10.4236/ojs.2015.53022

Finch, H. (2015). A comparison of statistics for assessing model invariance in latent class analysis. Open Journal of Statistics, 5(3), 1-19. https://doi.org/10.4236/ojs.2015.53022

Gambari, I. A., Gbodi, B. E., Olakanmi, E. U., \& Abalaka, E. N. (2016). Promoting intrinsic and extrinsic motivation among chemistry students using computer-assisted instruction. Contemporary Educational Technology, 7(1), 25-46.

Gasser, L., Grütter, J., Buholzer, A., \& Wettstein, A. (2018). Emotionally supportive classroom interactions and students' perceptions of their teachers as caring and just. Learning \& Instruction, 54, 82-92.

Griffin, N. L. (2018). Using assessment feedback for motivation among early adolescents: a grounded theory study. Liberty University.

Hagger, M. S., Koch, S., \& Chatzisarantis, N. J. D. (2015). The effect of causality orientations and positive competence-enhancing feedback on intrinsic motivation: a test of additive and interactive effects. Personality and individual differences, 72, 107-111.

Harter, S. (2012). The construction of the self, developmental and sociocultural foundations. Second edition. Guildford Press.

Harter, S., Waters, P., \& Whitesell, N.R. (1998). Relational self-worth: differences in perceived worth as a person across interpersonal context among adolescents. Child Development, 69(3), 756-766. https://doi.org/009-3920/98/6903-0019\$01.00

Hattie, J., \& Timperley, H. (2007). The Power of Feedback. Review of Educational Research, 77, 81. https://doi.org/10.3102/003465430298487

Hautamäki, J., \& Kupiainen, S. (2014). Learning to learn in Finland, theory and policy, research and practice. In R.D. Crick, C. Stringher \& K. Ren (Eds.) Learning to learn, international perspectives from theory and practice (pp. 179-205). Routledge.

Heimo, O. I., Rantanen, M. M., \& Kimppa, K. K. (2015). Wilma ruined my life: how an educational system became the criminal record for the adolescents. SIGCAS Computers \& Society, 45(3), 138-146.

Hoffman, J. (2008). I know what you did last math class. The New York Times. May 4, 2008. Retrieved from https://www.nytimes.com/2008/05/04/fashion/04edline.html

Hughes, G. B. (2010). Formative assessment practices that maximize learning for students at risk. In H. L. Andrack \& G. J. Cizek (Eds.) Handbook of formative assessment (pp. 212-232). Routledge.

Jeno, L. M., Grytnes, J.-A., \& Vandvik, V. (2017). The effect of a mobile-application tool on biology students' motivation and achievement in species identification: a self-determination theory perspective. Computers \& Education, 107, 1-12. https://doi.org/10.1016/j.compedu.2016.12.011

Kluger, A. N., \& DeNisi, A. (1996). The effects of feedback interventions on performance: a historical review, a meta-analysis, and a preliminary feedback intervention theory. Psychological Bulletin, 119(2), 254284.

Korhonen, J., Linnanmäki, K., \& Aunio, P. (2014). Learning difficulties, academic well-being and educational dropout: a person-centred approach. Learning and Individual Differences, 31, 1-10. https://doi.org/10.1016/j.lindif.2013.12.011

Kreuter, F., \& Muthén, B.O.L (2008). Longitudinal modeling of population heterogeneity: Methodological challenges to the analysis of empirically derived criminal trajectory profiles. In G. R. Hancock, \& K. M. Samuelsen (Eds.) Advances in latent variable mixture models (pp. 53-75). Information Age Publishing, Inc. 
Kuusimäki, A.-M., Uusitalo-Malmivaara, L., \& Tirri, K. (2019). Parents' and teachers' views on digital communication in Finland. Education Research International, 1-7. https://doi.org/10.1155/2019/8236786

Leary, M. R., \& Terry, M. L. (2012). Interpersonal aspects of receiving evaluative feedback. In R. Sutton, M. J. Hornsey, \& K. M. Douglas (Eds.) Feedback (pp. 15-28). Peter Lang Publishing.

Lenhard, W., \& Lenhard, A. (2016). Computation of Effect Sizes. Psychometrica. https://doi.org/10.13140/RG.2.2.17823.92329

Lindfors, P., Minkkinen, J., Rimpelä, A., \& Hotulainen, R. (2017). Family and school social capital, school burnout and academic achievement: a multilevel longitudinal analysis among Finnish pupils. International Journal of Adolescence and Youth, 23(3), 368-381. https://doi.org/10.1080/02673843.2017.1389758

Linnakylä, P., \& Malin, A. (2008). Finnish students' school engagement profiles in the light of PISA 2003. Scandinavian Journal of Educational Research, 52(6), 583-602.

Marsh, H. W., Lütdke, O., Trautwein, U., \& Morin, A. J. S. (2009). Classical latent profile analysis of academic self-concept dimensions: synergy of person- and variable-centered approaches in theoretical models of self-concept. Structural Equation Modelling: A Multidisciplinary Journal, 16, 191-225. https://doi.org/10.1808/10705510902751010

McKenna, K., Pouska, B., Moraes, M. C., \& Folkestad, J. E. (2019). Visual-form learning analytics: a tool for critical reflection and feedback. Contemporary Educational Technology, 10(3), 214-228. https://doi.org/10.30935/cet.589989

Niemivirta, M. (2004). Habits of mind and academic endeavours: The correlates and consequences of achievement goal orientations. University of Helsinki, Department of Education, Research Report 196. Helsinki University Press.

Nylund, K. L., Asparouhov, T., \& Muthén, B. O. (2007). Deciding on the number of classes in latent class analysis and growth mixture modeling: a monte carlo simulation study. A structural Equation Modeling 14(4), 535-569. https://doi.org/10.1080/10705510701575396

Oberski, D. (2016). Mixture models: latent profile and latent class analysis. In J. Robertson \& M. Kaptein (Eds.) Modern Statistical Methods for $\mathrm{HCl}$ (275-287). Springer.

Oinas, S., Vainikainen, M.-P. \& Hotulainen, R. (2017). Technology-enhanced feedback for pupils and parents in Finnish basic education. Computers \& Education, 108, 59-70. https://doi.org/10.1016/J.compedu.2017.01.012

Oinas, S., Vainikainen, M.-P., \& Hotulainen, R. (2018). Is technology-enhanced feedback encouraging for all? A person-centred approach. Learning \& Instruction, 58, 12-21. https://doi.org/10.1016/j.learninstruc.2018.05.002

Pekrun, R. (2009). Emotions at school. In K. R. Wentzel \& A. Wigfield (Eds.) Handbook of motivation at school (pp. 575-604). Routledge.

Pekrun, R., Cusack, A., Murayma, K., Elliot, A. J., \& Thomas, K. (2014). The power of anticipated feedback: effect on students' achievement goals and achievement emotions. Learning and Instruction 29, 115124. https://doi.org/10.1016/j.learninstruc.2013.09.002

Rawlings, A. M., Tapola, A., \& Niemivirta, M. (2017). Predictive effects of temperament on motivation. $\begin{array}{llll}\text { International Journal of Educational Psychology, 6(2), 148-182. } & \text {. }\end{array}$ https://doi.org/10.17583/ijep.2017.2414 
Reeve, J., Ryan, R., Deci, E. L., \& Jang, H. (2009). Understanding and promoting autonomous self-regulation: A self-determination theory perspective. In D. H. Schunk \& B. J. Zimmerman (Eds.) Motivation and selfregulated learning, theory, research and applications (pp. 223-244). Routledge.

Renninger, K. A., \& Hidi, S. (2011). Revisiting the conceptualization, measurement, and generation of interest. Educational psychologist, 46(3),168-184.

Rosenthal-von der Pütten, A. M., Hastall, M. R., Köcher, S., Meske, C., Heinrich, T., Labrenz, F., \& Ocklenburg, S. (2019). "Likes" as social rewards: their role in online social comparison and decisions to like other people's selfies. Computers in Human Behavior, 92, 76-86.

Ruzek, E. A., Hafen, C. A., Allen, J. P., Gregory, A., Mikami, A. Y., \& Pianta, R. C. (2016). How teacher emotional support motivates students: the mediating roles of perceived relatedness, autonomy support and competence. Learning \& Instruction, 42, 95-103.

Ryan, R. M., \& Deci, E. L. (2000a). Self-determination theory and the facilitation of intrinsic motivation, social development, and well-being. American Psychologist, 55(1), 68-78. https://doi.org/10.1037110003066X.55.1.68

Ryan, R. M., \& Deci, E. L. (2000b). Intrinsic and Extrinsic Motivations: Classic Definitions and New Directions. Contemporary Educational Psychology, 25, 54-67. https://doi.org/10.1006/ceps.1999.1020

Ryan, R. M., \& Stiller, J. (1991). The social contexts of internalization: parent and teacher influences on autonomy, motivation and learning. In M.L. Maehr \& P.L. Pintrich (Eds.) Advances in Motivation and achievement, volume 7 (pp. 115-149). JAI Press Inc.

Ryan, R. M., Stiller, J., \& Lynch, J.H. (1994). Representations of relationships to teachers, parents, and friends as predictors of academic motivation and self-esteem. The Journal of Early Adolescence, 14(2), 226249. https://doi.org/10.1177/027243169401400207

Schenke, K., Ruzek, E., Lam, A. C., Karabenik, S. A., \& Eccles, J. S. (2018). To the means and beyond: understanding variation in students' perceptions of teacher emotional support. Learning and Instruction, 55, 13-21.

Skinner, E., \& Edge, K. (2002). Self-determination, coping, and development. In E. L. Deci \& R. M. Ryan (Eds.) Handbook of self-determination research (pp. 297-337). The University of Rochester Press.

Tempelaar, D., Rienties, B., Mittelmeier, J., \& Nguyen, Q. (2018). Student profiling in a dispositional learning analytics application using formative assessment. Computers in Human Behavior, 78, 408-420. https://doi.org/10.1016/j.chb.2017.08.010

Tofighi, D., \& Enders, C. K. (2007). Identifying the Correct Number of Classes in a Growth Mixture Model. In G.R. Hancock (Eds.) Advances in Latent Variable Mixture Models (pp. 317-341). Information Age.

UCLA (2019). Latent class analysis, MPlus data analyses examples. Retrieved from https://stats.idre.ucla.edu /mplus/dae/latent-class-analysis/

Wang, M., \& Peck, S.C. (2013). Adolescent educational success and mental health vary across school engagement profiles. Developmental Psychology, 49(7), 1266-1276.

Wentzel, K. R. (2009). Students' relationships with teachers as motivational contexts. In K. R. Wentzel, \& A. Wigfield (Eds.) Handbook of Motivation at School (pp. 301-322). Routledge.

Wiliam, D. (2011). What is assessment for learning? Studies in Educational Evaluation, 37, 3-14.

Williams, G. A., \& Kibowski, F. (2016). Latent class analysis and latent profile analysis. In L. A. Jason \& D. S. Glenwick (Eds.) Handbook of methodological approaches to community-based research: qualitative, quantitative, and mixed methods (pp.143-152). Oxford University Press. 
Correspondence: Sanna Elina Oinas, University of Helsinki, Finland. E-mail: sanna.oinas@helsinki.fi 